\title{
Effect of the operating conditions on the anaerobic digestion of wheatgrass for chemicals and energy production
}

\author{
Igor M. O. Silva ${ }^{1} \cdot$ Davide Dionisi $^{1}$
}

Received: 13 December 2019 / Revised: 9 April 2020 / Accepted: 16 April 2020 / Published online: 8 June 2020

(C) The Author(s) 2020

\begin{abstract}
The aim of this study was to investigate anaerobic digestion of wheatgrass in the absence of hydrolytic pre-treatments. The effect of solids retention time (SRT) (1-64 days), inoculum acclimation (0-80 days acclimation), temperature $\left(40-70{ }^{\circ} \mathrm{C}\right)$ and buffer capacity (20-200 mM phosphate buffer) on conversion of the feedstock, yield and composition of liquid-phase products (ethanol and short-chain organic acids, SCOAs) and COD removal was investigated in semi-continuous (intermittent feed) completely mixed reactors. SRT had the most important effect on process performance. Biodegradation of the feedstock was favoured at high SRT, with $61 \%$ removal of volatile suspended solids and $84 \%$ removal of total carbohydrates at SRT 64 days. However, low yield of liquid-phase products was observed at high SRT because of strong methanogenic activity (57\% removal of the total COD). The highest yield of liquid-phase products was 20\% (COD basis) at SRT 8 days. Although high biodegradation of the feedstock was observed after long-term batch acclimation (30 and 80 days), once the digestion conditions were switched to semicontinuous at short SRT ( 2 days), the biodegradation of the feedstock decreased considerably. The best process performance was observed at $40{ }^{\circ} \mathrm{C}$.
\end{abstract}

Keywords Anaerobic digestion $\cdot$ Carboxylates $\cdot$ Lignocellulose $\cdot$ Grass $\cdot$ Biorefinery

\section{Introduction}

Anaerobic digestion (AD) of biomass, often organic waste, is typically used across the globe for the generation of methane to be converted into energy. In recent years, the possible use of $\mathrm{AD}$ in a biorefinery context to produce bio-based products such as short-chain organic acids (SCOAs) and hydrogen is becoming of interest $[1,2]$. The use of organic waste to produce these chemicals is attractive because of the nonrenewable nature of the feedstocks often used in current commercial processes.

According to our recent study [3], on a global scale, the current energy generation by anaerobic digestion is only a minor fraction of the total potential energy that could be

Davide Dionisi

davidedionisi@abdn.ac.uk

Igor M. O. Silva

igormosilva@gmail.com

1 Chemical and Materials Engineering Group, School of Engineering, University of Aberdeen, Aberdeen AB24 3UE, UK generated based on the generation rate of organic waste. One of the limitations in the use of anaerobic digestion for energy or chemicals production is the lignocellulosic nature of many types of organic waste (e.g. agricultural residues). Lignocellulosic biomass, characterised by the presence of lignin, cellulose and hemicellulose, is typically slowly biodegradable and this has so far limited its use as feedstock for anaerobic digesters.

Many literature studies on the use of lignocellulosic biomass for fermentation purposes performed pre-treatments of the feedstock before the fermentation stage [4]. The aim of the pre-treatments is to hydrolyse the lignin and cellulosic components of biomass, converting the cellulosic components into sugars that can be easily digested. Pre-treatments usually require alkaline or acidic solutions, enzymes (e.g. cellulase, cellobiase and xylase) and/or energy [5,6]. Although the pre-treatments usually give good yields of carbohydrates released or converted from the feedstock, the costs associated with chemicals, enzymes and/or energy in the pre-treatment and hydrolysis steps are expensive for industrial scale.

As an alternative to hydrolytic pre-treatments, microorganisms in $\mathrm{AD}$ processes are in principle able to develop the enzymes required to hydrolyse lignin and cellulose. 
Therefore, an AD process of lignocellulosic biomass without hydrolytic pre-treatments is, at least in theory, possible. However, little investigation has been reported in the literature on the use of lignocellulosic biomass for $\mathrm{AD}$ without hydrolytic pre-treatments.

The novelty and aim of this study is the experimental investigation of the $\mathrm{AD}$ of lignocellulosic substrates without hydrolytic pre-treatments. As an example of lignocellulosic biomass, we used wheatgrass, in particular the young shoots of the crop Triticum aestivum (common wheat). The lignin, cellulose and hemicellulose content of wheatgrass and of other grasses depends on the species, on the growth conditions and on the age of the grass at harvest $[7,8]$. For example, the lignin content of young (27 days) wheat plants was in the range 4$8 \%$ [9]. The neutral detergent fibre (approximately corresponding to the sum of cellulose, hemicellulose and lignin) and the acid detergent fibre (approximately corresponding to the sum of cellulose and lignin) were 15-17\% and 5-7\%, respectively, in several varieties of wheatgrass sprouts at 5day age [10]. Wheatgrass belongs to the family of Gramineae, which can grow in non-arable lands without direct competition with food production or requirement of fertilizers or pesticides. Owing to its widespread growth on land, Gramineae have been considered as a potential lignocellulosic feedstock for biochemicals and bioenergy production [11]. The substrate used in this study had only been subject by the manufacturer to the pre-treatments of particle reduction (milling) and drying, which do not alter the chemical structure of the feedstock.

Our study investigated the effect of operating conditions (residence time, acclimation of the inoculum, temperature and $\mathrm{pH}$ ), on substrate conversion, yield and composition of liquid-phase products and COD removal in semi-continuous (intermittent feed) experiments.

\section{Material and methods}

\subsection{Feedstock of the reactors}

Wheatgrass powder obtained from sprouts of the Triticum aestivum L. (Bulk Powders, UK) was used as the lignocellulosic substrate for the fermentation process. The substrate was produced from raw wheatgrass after drying and grinding and was comprised of a fine powder (200 mesh) of $100 \%$ wheatgrass with $50 \%$ of carbohydrates, $25 \%$ of proteins and $25 \%$ of fibre [12]. The feed of the reactors consisted in a suspension of $20 \mathrm{~g} / \mathrm{l}$ of wheatgrass in tap water. The suspension also contained the following mineral salts: $\mathrm{K}_{2} \mathrm{HPO}_{4}, 17.4 \mathrm{~g} / \mathrm{l}$; $\mathrm{NaH}_{2} \mathrm{PO}_{4}, 12.0 \mathrm{~g} / \mathrm{l} ; \mathrm{NH}_{4} \mathrm{Cl}, 2 \mathrm{~g} / \mathrm{l} ; \mathrm{MgCl}_{2} \cdot 6 \mathrm{H}_{2} \mathrm{O}, 0.125 \mathrm{~g} / \mathrm{l}$; $\mathrm{CaCl}_{2} \cdot \mathrm{H}_{2} \mathrm{O}, 0.09 \mathrm{~g} / \mathrm{l}$. This suspension corresponded to a concentration of phosphate buffer of $200 \mathrm{mM}$ and Table 1 presents the characterisation of the feedstock suspension. In the run with low concentration of phosphate buffer $(20 \mathrm{mM}$, Run
13 in Table 2), the concentration of $\mathrm{K}_{2} \mathrm{HPO}_{4}$ and $\mathrm{NaH}_{2} \mathrm{PO}_{4}$ was $1.74 \mathrm{~g} / 1$ and $1.2 \mathrm{~g} / 1$, respectively.

\subsection{Experimental setup}

A summary of the experimental conditions in all the runs is reported in Table 2. The scheme of the reactor set-up is shown in Fig. 1. Stirred (magnetic bar at $250 \mathrm{rpm}$ ) jacketed glass vessels of $200 \mathrm{ml}$ working volume ( $300 \mathrm{ml}$ total volume) were used as fermenters. The circulating water in the jacket was provided by a heating circulator and used to control the fermentation broth temperature at the desired value. A thermostat was dipped into the fermentation broth to measure the temperature. A silicone tubing was connected to the fermentation broth for sampling with a volumetric pipette. The effluent was collected continuously with an overflow tubing set to maintain the working volume at $200 \mathrm{ml}$, and the outlet silicone tubing was bent in a $U$ shape to prevent oxygen entrance and maintain anaerobic conditions inside the fermenter. The system was well mixed and the SRT (solids retention time) coincided with the HRT (hydraulic retention time).

The wheatgrass suspension used as feed for the reactors was also continuously stirred with a magnetic bar at $250 \mathrm{rpm}$. A peristaltic pump was used for feeding. The pump had been previously calibrated at flowrate of $25 \mathrm{ml} / \mathrm{min}$ and was used to pump intermittently the feed suspension to the fermenter. The pump was switched on for $1 \mathrm{~min}$ via a programmable power management system, so that each feeding cycle corresponded to feeding of $25 \mathrm{ml}$ into each reactor. The flowrate and feeding time were maintained constant in all the runs to preserve the same flow regime and residence time of particles in the pumping system, respectively.

Each experimental run was initiated by filling the fermenter with fresh feedstock suspension and subsequently sealing the vessel from the atmospheric air with a multi-port lid of polytetrafluoroethylene. Nitrogen gas (oxygen-free) was used to sparge for $5 \mathrm{~min}$ the suspension in the fermenter and favour an anaerobic condition inside the vessel. The inoculum was taken from the digestate of a commercial anaerobic digester (Gask Farm, Turriff, Aberdeenshire, UK). The digester treats food industry and agricultural waste and operates at $38-40^{\circ} \mathrm{C}$. The inoculum concentration used to start-up the reactor was $1 \mathrm{~g} \mathrm{VSS} / \mathrm{l}$. The inoculum was stored in fridge $\left(2{ }^{\circ} \mathrm{C}\right)$ in order to maintain freshness and minimise its degradation and was maintained at room temperature for $24 \mathrm{~h}$ before use, similarly to other literature studies [13]. The inoculum was used without acclimation to the feedstock, except for the runs (Runs 8 and 9) which investigated the effect of acclimation. In these runs, the inoculum was acclimated to the feed suspension in batch for the specified length of time, before the cultivation conditions were switched to semi-continuous.

The length of the fermentation runs was at least 3.5 times the SRT, with a minimum of 40 days, in order to obtain 
Table 1 Characterization of the feedstock suspension. TS total solids, VS volatile solids, TSS total suspended solids, VSS volatile suspended solids, TC total carbohydrates, $S C$ soluble carbohydrates, $T C O D$ total chemical oxygen demand, $S C O D$ soluble chemical oxygen demand

\begin{tabular}{lllllllll}
\hline TS $(\mathrm{g} / \mathrm{l})$ & $\mathrm{VS}(\mathrm{g} / \mathrm{l})$ & $\mathrm{TSS}(\mathrm{g} / \mathrm{l})$ & $\mathrm{VSS}(\mathrm{g} / \mathrm{l})$ & $\mathrm{TC}(\mathrm{g} / \mathrm{l})$ & $\mathrm{SC}(\mathrm{g} / \mathrm{l})$ & $\mathrm{TCOD}(\mathrm{g}$ COD$/ \mathrm{l})$ & $\mathrm{SCOD}(\mathrm{g} \mathrm{COD} / \mathrm{l})$ & $\mathrm{pH}$ \\
\hline 24 & 19 & 22 & 17 & 10.1 & 1.7 & 24 & 3 & 6.8 \\
\hline
\end{tabular}

enough data to calculate the average values at steady state of the measured variables. The average values for each run were calculated from all the samples collected during the run, ignoring the samples collected during the first three SRTs, which was considered the time necessary to reach the steady state.

\subsection{Analytical procedures}

The reactors were sampled once or twice per week. At each sample day, the fermentation broth was sampled to measure the concentration of VSS, TC, fermentation products, TCOD and the $\mathrm{pH}$.

An aliquot of $5 \mathrm{ml}$ of the fermentation broth was sampled with a volumetric pipette to filter in a pre-weighted glass-fibre filter paper to determine the VSS concentration. Aliquots samples of $1 \mu \mathrm{l}$ of the filtrate broth were used to determine the concentration of the fermentation products (acetic, propionic and butyric acid and ethanol) on GC-FID using a capillary column $\left(30 \mathrm{~m} \times 0.25 \mathrm{~mm}\right.$, Thermo Scientific TraceGOLD ${ }^{\mathrm{TM}}$ TG-WaxMS A). The initial temperature of the column was $80{ }^{\circ} \mathrm{C}$ for $2 \mathrm{~min}$ followed with a ramp of $20{ }^{\circ} \mathrm{C} / \mathrm{min}$ and a final temperature of $200^{\circ} \mathrm{C}$ for $1 \mathrm{~min}$; the injector and detector temperatures were $200^{\circ} \mathrm{C}$ and $250^{\circ} \mathrm{C}$ respectively. Hydrogen was used as the carrier gas at a flowrate of $35 \mathrm{ml} / \mathrm{min}$. The samples were acidified with $\mathrm{H}_{3} \mathrm{PO}_{4}(30 \% \mathrm{v} / \mathrm{v})$, and 2-ethylbutyric acid was used as internal standard. Total and soluble carbohydrates were measured according to the Anthrone method. Total and soluble COD (TCOD and SCOD) were measured in Spectroquant ${ }^{\circ}$ COD cell test (Merck COD kits, Germany). An aliquot of $3 \mathrm{ml}$ of the fermentation broth was used to measure the $\mathrm{pH}(\mathrm{pH}$ meter Metler Toledo, Switzerland).

\subsection{Calculations}

The COD conversion factors for the fermentation products were calculated according to their respective oxidation stoichiometries. The removal of VSS, TC and TCOD were calculated according to Eqs. (1-3):

VSS removal $(\%)=\left(1-\frac{\text { VSS in the fermentate }\left(\frac{g}{l}\right)}{\text { VSS in the feed }\left(\frac{g}{l}\right)}\right) \times 100 \%$

TC removal $(\%)=\left(1-\frac{T C \text { in the fermentate }\left(\frac{g}{l}\right)}{T C \text { in the feed }\left(\frac{g}{l}\right)}\right) \times 100 \%$

TCOD removal $(\%)=\left(1-\frac{T C O D \text { in the fermentate }\left(g \frac{C O D}{l}\right)}{T C O D \text { in the feed }\left(g \frac{C O D}{l}\right)}\right) \times 100 \%$

Table 2 Summary of experimental conditions in all the runs. $O L R=$ organic load rate

\begin{tabular}{lllllll}
\hline & SRT $(\mathrm{d})$ & $\mathrm{T}\left({ }^{\circ} \mathrm{C}\right)$ & Interval between feeds $(\mathrm{d})$ & Pre-acclimation & Buffer concentration (mM) & OLR (gCOD/1 day) \\
\hline Run 1 & 1 & 40 & 0.125 & No & 200 & 24 \\
Run 2 & 2 & 40 & 0.25 & No & 200 & 12 \\
Run 3 & 4 & 40 & 0.5 & No & No & 6 \\
Run 4 & 8 & 40 & 1 & No & 200 & 3 \\
Run 5 & 16 & 40 & 2 & No & 200 & 1.5 \\
Run 6 & 32 & 40 & 4 & No & 200 & 0.75 \\
Run 7 & 64 & 40 & 8 & $30 \mathrm{~d}$ & 0.375 \\
Run 8 & 2 & 40 & 0.25 & $80 \mathrm{~d}$ & 200 & 12 \\
Run 9 & 2 & 40 & 0.25 & No & 200 & 12 \\
Run 10 & 2 & 50 & 0.25 & No & 200 & 12 \\
Run 11 & 2 & 60 & 0.25 & No & 200 & 12 \\
Run 12 & 2 & 70 & 0.25 & No & 200 & 12 \\
Run 13 & 2 & 40 & 0.25 & 20 & \\
\hline
\end{tabular}




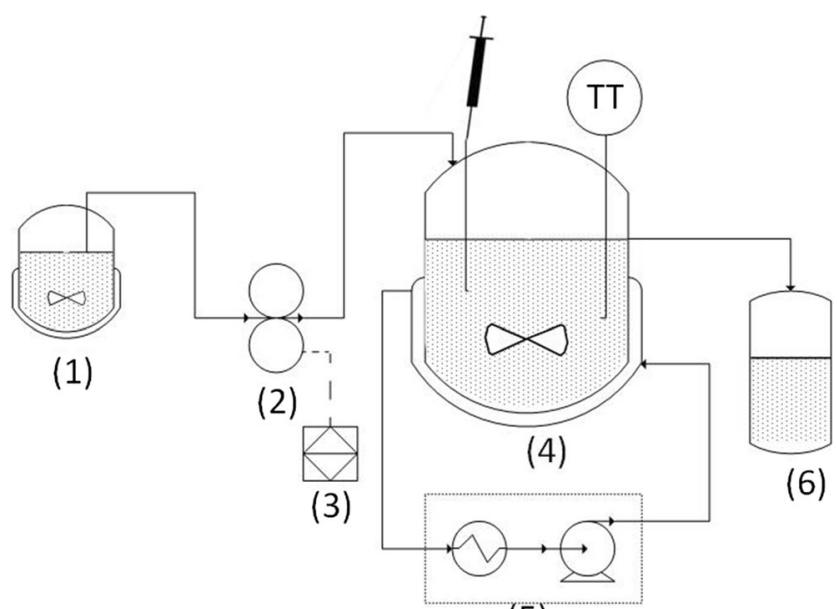

(5)

Fig. 1 Scheme of the experimental set-up. (1) Feedstock solution; (2) Peristaltic pump; (3) Programmable power management system; (4) Fermentation glass vessel containing a magnetic stir bar, one sampling tubing and a thermostat; (5) Heating circulator; (6) Effluent

The yield of each liquid-phase product was calculated by dividing the concentration of each substance, in COD units, by the total COD of the feed. The total product yield was calculated by adding together the concentrations of all the liquid-phase products (in COD units) and dividing by the total COD of the feed (Eq. (4)):

Total products yield $(\%)$

$$
=\frac{\sum \text { Products in the fermentate }(g C O D / l)}{\text { Feed concentration }(g C O D / l)} \times 100 \%
$$

The methane yield on the VS (volatile solids) of the feed was calculated for Run 7 (SRT $64 \mathrm{~d}$ ) at steady state because in this run, a high removal of the TCOD was observed. The methane yield was calculated from the COD balance, which states that under anaerobic conditions, any removal of TCOD from the liquid-solid phase is due to COD leaving the system with the gas phase [14]. The species that can account for the COD leaving with the gas phase are hydrogen and methane, but in the conditions of Run 7, it is reasonable to assume that methane and not hydrogen was the main product (this will be discussed in the Sect. 3, Sect. 3.1). The steps in the calculation of the methane yield were the following:

- The TCOD of the feed was multiplied by the average TCOD removal at steady state to obtain the average mass of TCOD removed per unit volume of the reactor $(\mathrm{kg}$ $\left.\mathrm{COD} / \mathrm{m}^{3}\right)$

- The mass of TCOD removed per unit volume of the reactor was divided by the COD conversion factor for methane $(4 \mathrm{~kg} \mathrm{COD} / \mathrm{kg} \mathrm{CH}$, calculated from the stoichiometry of total oxidation of methane) to obtain the methane production per unit volume of the reactor $\left(\mathrm{kg} \mathrm{CH} / \mathrm{m}^{3}\right)$
- The methane production per unit volume of the reactor was converted into volume $\left(\mathrm{m}^{3} \mathrm{CH} 4 / \mathrm{m}^{3}\right)$ using the ideal gas law at the temperature of the reactor $\left(40{ }^{\circ} \mathrm{C}\right)$, which gives a methane density of $0.62 \mathrm{~kg} / \mathrm{m}^{3}$

- The volumetric methane production per unit volume of the reactor was divided by the VS concentration of the feed to obtain the methane production per unit of VS $\left(\mathrm{m}^{3}\right.$ $\mathrm{CH} 4 / \mathrm{kg}$ VS)

\section{Results and discussion}

\subsection{Effect of SRT}

The effect of SRT was investigated in runs 1-7. The time profiles of VSS and TC removal and of the total yield of products are shown in Fig. 2, while the average values at steady state of VSS, TC and TCOD removal from the liquid-solid phase are shown in Fig. 3. The general trend shows an increase in VSS, TC and TCOD removal with increasing SRTs. Whilst the VSS reduced only $9 \%$ at SRT of 1 day, a reduction of over $60 \%$ was observed in the VSS for the SRT at 64 days. Regarding TC removal, whilst approximately $15 \%$ of TC concentration reduced for the fermenter at SRT of 1 day, over $84 \%$ of TC reduction was observed at SRT of 64 days. No TCOD removal from the liquid phase was observed for SRT 1-4 days. TCOD removal was only observed for SRT values of 8 days or higher and reached the highest value of $57 \%$ at 64 days of SRT. The total products yield was between 10 and 20\% (COD basis) for runs at SRT 1-8 days and SRT 32 days, while it was virtually negligible in the runs at SRT 16 and 64 days. The maximum yield of total products was $20 \%$ (COD basis) for SRT 8 days. In all runs, the removal of soluble carbohydrates was complete after 2 days of start-up (data not shown).

The general evidence from Fig. 3 is that in all runs some hydrolysis of the insoluble material in the feed was observed, as indicated by the removal of VSS. It should be noted that microorganisms generated in the fermentation contribute to the VSS, which complicates the analysis of VSS removal. However, the production of microorganisms in anaerobic digestion is low (for example the study by Kalyuzhnyi [15] reports literature and own values for anaerobic growth yields, the highest value being $0.12 \mathrm{~g} / \mathrm{g}$ of glucose for acidogenic microorganisms) and therefore, VSS removal can be used for a qualitative indication of the removal of the insoluble organic matter in the feed. In most runs, removal of insoluble carbohydrates was also observed, as indicated by the fact that the removal of SC corresponded to about $17 \%$ of the total carbohydrates in the feed, and the removal of TC was, in all runs except the one at SRT 1 day, higher than this value. Acetate was the main component in the fermentation products, 

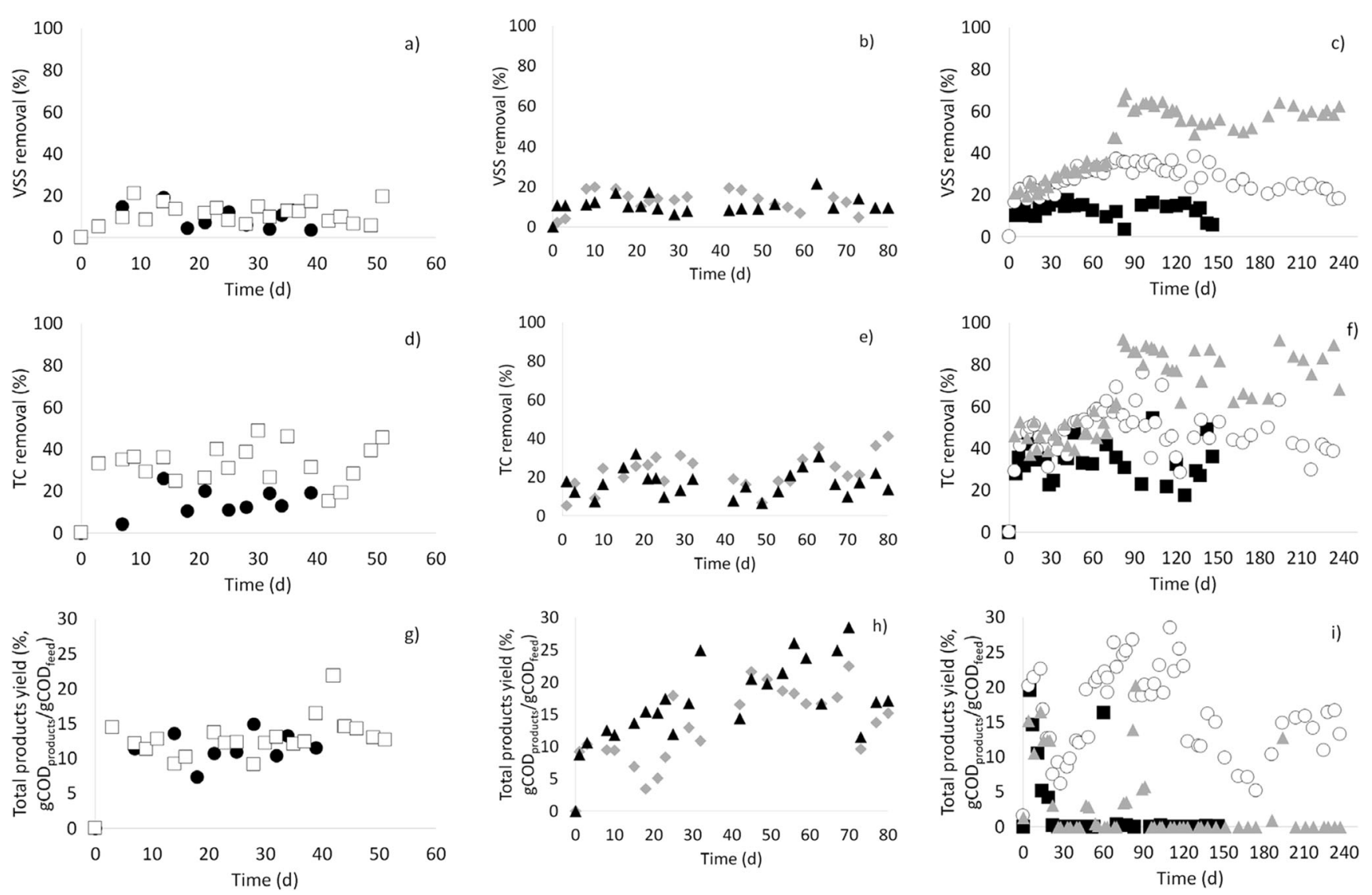

Fig. 2 Time profiles for the fermentation runs (Runs 1-7) as a function of the SRT. a-c VSS removal. $\mathbf{d}-\mathbf{f}$ TC removal. $\mathbf{g}-\mathbf{i}$ Total products yield. a, $\mathbf{d}$ and $\mathbf{g}$ show runs at SRT 1 day (O), 2 days $(\square)$. b, e, h show runs at

SRT 4 days $(\diamond), 8$ days $(\boldsymbol{\Delta})$. c, f, i show runs at SRT 16 days $(\square)$, 32 days $(\bigcirc), 64$ days $(\triangle)$

followed by propionate and butyrate. Throughout this study, the composition of the products remained relatively constant and unaffected by the process conditions, and also remained relatively constant within each run.

The generation of gas-phase products (hydrogen and/or methane) was estimated, using the COD balance (see Sect. 2, Sect. 2.3), from the removal of TCOD from the liquidsolid phase. The use of the COD balance has been shown to give accurate estimations of methane production in methanogenic anaerobic digesters in many experimental studies (e.g. $[16,17])$. Thermodynamic considerations (not shown) on the gas-liquid equilibrium of the other products (short-chain organic acids and ethanol) allow to exclude any significant losses of these substances with the gas phase. From Fig. 3, the general evidence is that for SRT, 1-4 days all the fermentation products were present in the liquid-solid phase (no reduction in the TCOD of the liquid-solid phase), while at longer SRT, the generation of gas-phase products gradually increased in importance. Gas-phase products became the main fermentation products at the longest investigated SRT, 64 days, where none of the analysed liquid-phase products (acetic, propionic, butyric and ethanol) were detected for most of the run. Although our experimental set-up did not distinguish between hydrogen and methane, the high COD removal at SRT
Fig. 3 Average values at steady state for Runs 1-7. a Removal from the liquid-solid phase of VSS ( $\square$ ), TC ( $\square$ ) and TCOD (口); (b) Products yield: acetate $\square$, propionate $(\square)$, butyrate $(\square)$ and ethanol $(\square$ ).

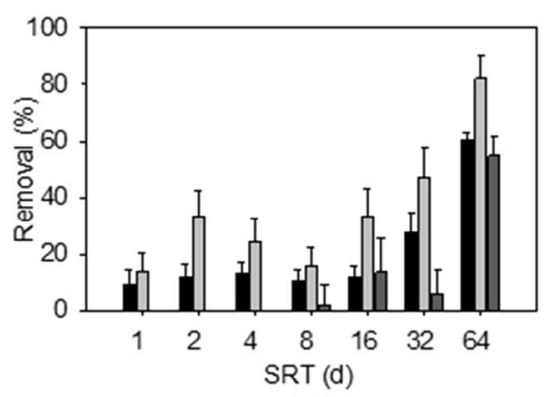

(a)

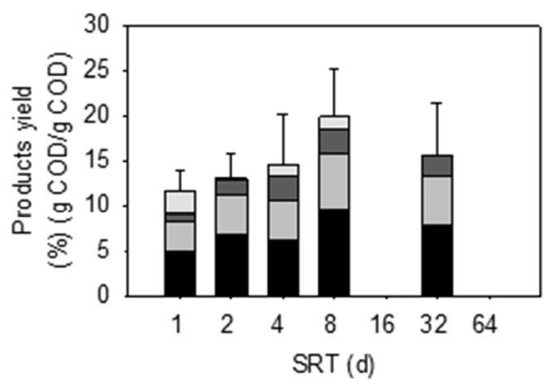

(b) 
64 days is clearly an indication that methanogenesis was taking place, for the following reasons. Firstly, hydrogen generation from the fermentation of organic species can only account for up to $30-35 \%$ of the COD of the feedstock [1] whereas TCOD removal at SRT 64 days was $57 \%$. The $30-35 \%$ COD conversion into hydrogen is a theoretical maximum and is usually not achieved under anaerobic digestion conditions, unless the process conditions are carefully selected to prevent the growth of hydrogen consuming bacteria (e.g. pre-treatment of the inoculum or low $\mathrm{pH}$ ). Secondly, unless the growth of hydrogen consuming bacteria is inhibited by other process conditions (as just described), hydrogen production from $\mathrm{AD}$ is usually associated with short SRT, typically less than 1 day [18], while in this case, the SRT was much longer and typical of methanogenic conditions. Thirdly, virtually, no removal of TCOD was observed in the runs at the shortest SRTs (1-4 days), where hydrogen generation was expected. This indicates that with the composition of the considered feedstock, hydrogen producing and hydrogen consuming reactions were balanced, with no net production of hydrogen under any conditions. Assuming, as justified above, that the $57 \%$ reduction in TCOD of the liquid phase obtained at SRT 64 days is entirely due to methane production, the methane yield at this SRT corresponds to $0.29 \mathrm{~m}^{3} \mathrm{CH}_{4} / \mathrm{kg}$ VS.

The runs at the three longest values of SRT showed a non-monotonic trend in the products yield (Fig. 3b), with negligible yield at SRT 16 and 64 days and higher product yield at SRT 32 days. The reason for this behaviour is not clear although it can be hypothesised that SRT 16-32 days is a borderline residence time between the conditions of full acidogenesis (observed for runs at SRT up to 8 days) and full methanogenesis (observed at SRT $64 \mathrm{~d}$ ). The run at SRT 32 days showed alternation of periods of high and low product yield, indicating instability, while the run at SRT 16 days showed the absence of liquid-phase products throughout most of the operating period (Fig. 2i). Possibly, in the intermediate range of SRT, the process behaviour can shift from the acidogenic to the methanogenic behaviour due to small changes in the process conditions, for example in the activity of the microbial populations in the inoculum. However, with the experimental data collected in this study, we have no proof for this hypothesis and the behaviour of the process at intermediate values of the SRT deserves further investigation.

The run at the longest SRT (64 days) showed an interesting profile for the VSS and TC removal (Fig. 2c and f). The removal of VSS and TC increased gradually from the start of the run until approximately day 70 , when a sharp increase in their removal was observed. These profiles indicate the slow phenomena of growth and acclimation on the lignocellulosic substrate. In this run, the concentration of total products (Fig. 2i) was high in the initial days after start-up, and then decreased virtually to zero, indicating acclimation and growth of methanogenic microorganisms. However, in coincidence with the step increase in VSS and TC removal, the concentration of total products also showed a step increase, but it came back to negligible values within a few days. These profiles indicate that the increase in the hydrolysis and acidogenesis rate of the microbial culture was not initially matched by the methanogenesis rate, but in a few days, methanogenic microorganisms were able to grow fast enough and to be able to metabolise the acids to methane at an increased rate. A similar sharp increase in methane generation was also observed by Turick et al. [19] during the batch anaerobic digestion of woody biomass, after more than 50 days of digestion. In that case, however, the products in the liquid phase were not measured.

In general, the boundary between acidogenic and methanogenic activity was around of 8-32 days of SRT. This shift between acidogenic and methanogenic microorganisms varying the SRT was also observed by several researchers for grass [20] and other organic substrates [21]. Since methanogens are slow growers, a minimum SRT is required to observe methane production for a particular feedstock. Since these studies aimed at biomethane production, the production of SCOAs and drop in the $\mathrm{pH}$ at low SRTs was considered a fermentation failure.

To further illustrate the mass balances, Fig. 4 shows the fate of the total COD of the feed in runs 1-7. When the COD conversion was mainly directed to liquid-phase products, the maximum conversion of the feed COD was 22\% (runs at SRT 8 and 32 days), with $78 \%$ of the feed COD being either unconverted or converted into microorganisms. When the COD conversion was directed to methane, the majority of the feed COD was converted (run at SRT 64 days).

The highest reduction in TCOD obtained in this study, $57 \%$, which corresponds to $0.29 \mathrm{~m}^{3} \mathrm{CH}_{4} / \mathrm{kg} \mathrm{VS}$, indicates one of the highest methane productions reported in the literature for lignocellulosic substrates without hydrolytic pre-treatments. Tong et al. [22] reported up to $0.36 \mathrm{~m}^{3} \mathrm{CH}_{4} / \mathrm{kg}$ VS for corn stover (10\% lignin) with a digestion time of 70 days. Sharma et al. [23] reported methane yields on Ipomoea fistulosa leaves (25\% lignin) of up to $0.39-0.43 \mathrm{~m}^{3} \mathrm{CH}_{4} / \mathrm{kg}$ VS with a digestion time of 8 weeks. Turick et al. [19] reported methane yields in the range $0.27-0.32 \mathrm{~m}^{3} \mathrm{CH}_{4} / \mathrm{kg} \mathrm{VS}$ for various types of woody biomass with a digestion time of 100 days. Only limited investigation has been carried out on the anaerobic digestion of wheatgrass, the substrate used in this study. Our previous study on wheatgrass [24], reported up to $50 \%$ removal of TC in batch tests after a digestion time of 150 days. Romano et al. [25] investigated the anaerobic digestion of Jose Tall Wheat Grass in batch tests (up to 21 days), with or without enzyme addition. Without enzyme addition, they reported methane yields of up to $0.22 \mathrm{~m}^{3} \mathrm{CH} 4 / \mathrm{kg} \mathrm{VS}$, which increased up to $0.29 \mathrm{~m}^{3} \mathrm{CH} 4 / \mathrm{kg}$ VS with the addition of enzymes. Lalak et al. [26] investigated the anaerobic digestion of Agropyron elongatum (Tall Wheat Grass) with and 
Fig. 4 Fate of the TCOD of the feed in Runs $1-7$ at steady state:

$\square$, converted to liquid-phase products; $\square$, converted to methane; $\square$, unconverted plus converted to microorganisms
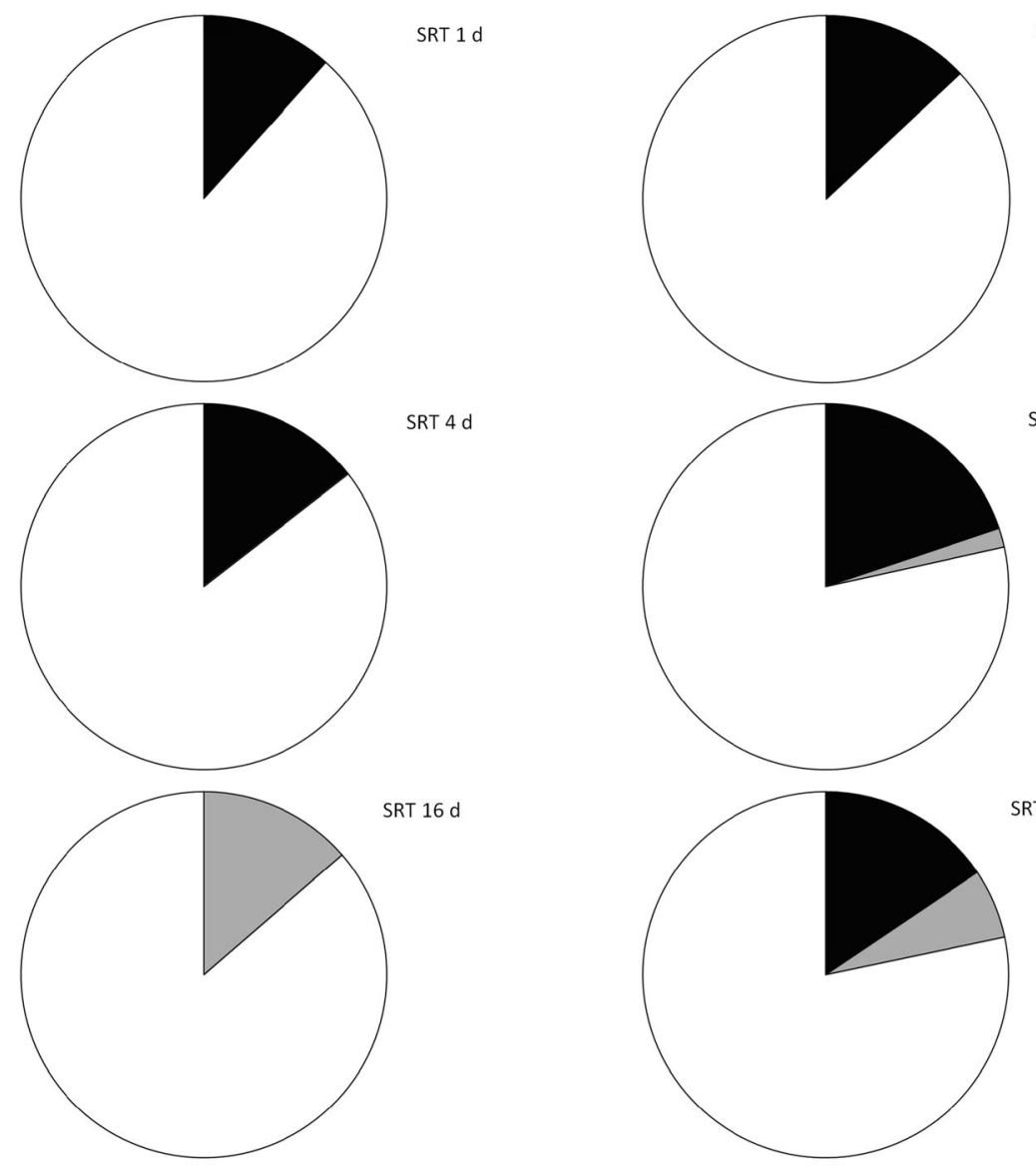

SRT 2 d
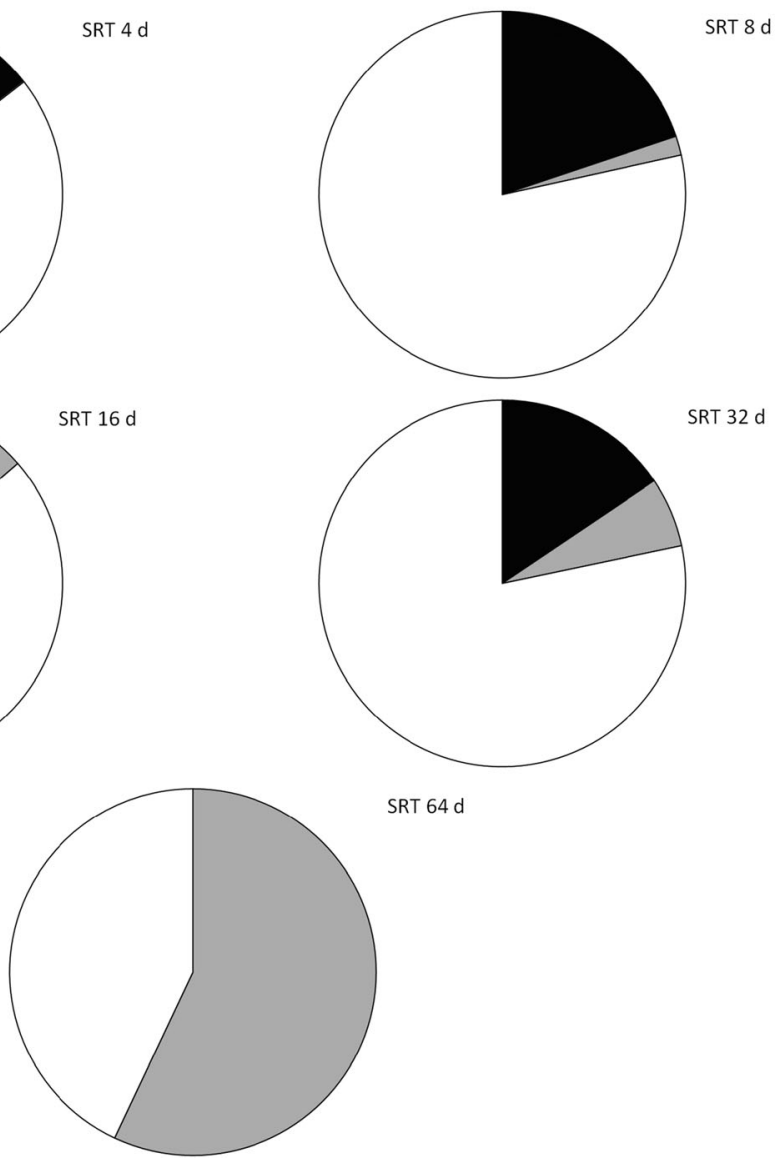

SRT $64 \mathrm{~d}$ without fungi pre-treatment in batch experiments. The methane yield in the test without pre-treatment was $0.13 \mathrm{~m}^{3} \mathrm{CH} 4$ / $\mathrm{kg}$ VS, which increased to $0.17 \mathrm{~m}^{3} \mathrm{CH} 4 / \mathrm{kg}$ VS with fungi pretreatment. In comparing our results with the literature, it is important to observe that the different growth stage of the biomass used may influence the results. Indeed, the content of lignin and cellulose changes during germination and growth of the biomass and this can affect its anaerobic biodegradation. There is evidence that the fibre content increases in the initial stages of grass growth [8] and that anaerobic digestion is favoured if the feedstock is harvested in the juvenile crop stages [7]. Our study was carried out with young wheatgrass shoots which are likely to be more biodegradable than more mature biomass. Further study is needed to compare the anaerobic biodegradability of young and more mature wheatgrass plants.
As far as the effect of process conditions is concerned, our study is the first to investigate anaerobic digestion of wheatgrass in a semi-continuous process and the effect of the SRT on acidogenic and methanogenic digestion. Furthermore, our study is the first to investigate the use of wheatgrass for the production of chemicals as alternative products to methane.

\subsection{Effect of inoculum acclimation}

The effect of acclimation was investigated by comparing runs 8 and 9 with Run 2. Acclimation is a period in which microorganisms adapt and adjust to the new environment with a particular substrate, $\mathrm{pH}$ and temperature. In runs 1-7 (presented previously), the semi-continuous mode began on the inoculation day. However, an acclimation of the inoculum in batch mode provides some time for the microorganisms to adapt to 
the new environment. Figure 5 shows the time profiles in the runs with different acclimation time (runs 8 and 9) and Fig. 6 shows the average values. The initial conditions in the runs with acclimated microorganisms showed high removal of VSS and $\mathrm{TC}$, the removal being higher at the longer acclimation time. This indicates that during the batch acclimation, the microorganisms were active and developed the ability to hydrolyse and metabolise the substrate. However, during the semi-continuous run, the removal of VSS and TC decreased rapidly, and, at steady state, the performance of the acclimated process was only slightly better than for the unacclimated one at steadystate condition (Fig. 6). A slight increase in the average values of VSS and TC removal and product yield was observed for the fermenter with acclimated inoculum. Whilst the VSS and TC removals were around 12 and 33\%, respectively, the VSS and TC removal increased to $15-16 \%$ and $39-40 \%$ when the inoculum was acclimated respectively. According to Fig. 6 b, the total product yield increased from 13 to $18-20 \%$ $\mathrm{gCOD} / \mathrm{gCOD}_{\text {feed }}$ when acclimation was applied in the fermenters.

Acclimation can be an important phase in which the microorganisms can adapt and evolve to the unfamiliar environment and substrate. In this study, considerable grass degradation was observed when the inoculum was acclimated for long periods under batch conditions. However, when the fermenter was set at semi-continuous mode, the substrate removal and products yields were only slightly better than observed in the reactors without inoculum acclimation. The low SRT applied in these experiments ( 2 days) is likely the main reason for the decrease in performance of the microorganisms. This indicates that the acclimated microorganisms were slow growers that were washed out at the relatively short SRT applied in these runs.

Possibly, the combination of batch inoculum acclimation and continuous processing at SRT values longer than 2 days might give a better performance in terms of feedstock removal and yield of liquid-phase products. Very few studies tried to use inoculum acclimation to improve the substrate degradation/hydrolysis [27] but their studies were usually operated in batch condition with no investigation of the ability of the acclimated microorganisms to be retained in continuous flow processes.

\subsection{Effect of temperature}

The effect of temperature was investigated by comparing runs 10-12 with Run 2 . Average values at steady state of these runs are shown in Fig. 7. The general trend indicates a slight decrease in VSS and TC removal at $50-60{ }^{\circ} \mathrm{C}$ and a more significant decrease at $70{ }^{\circ} \mathrm{C}$. Similar observations can be made for the generation of liquid-phase products. No removal of the TCOD was observed in these runs. Regarding the products
50

a)

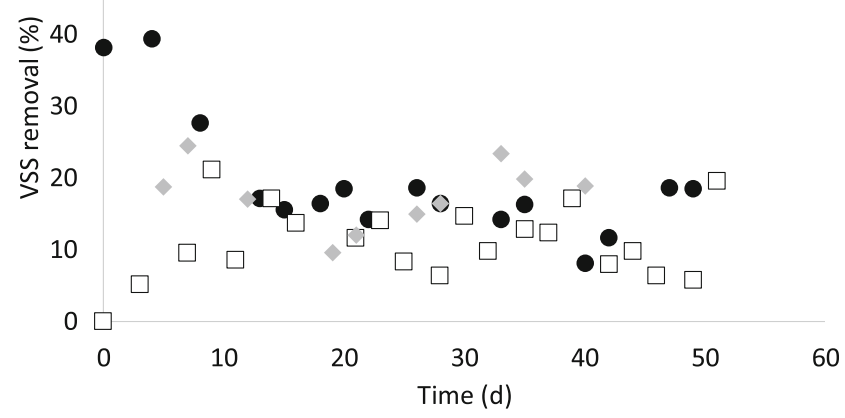

100

90

b)

80
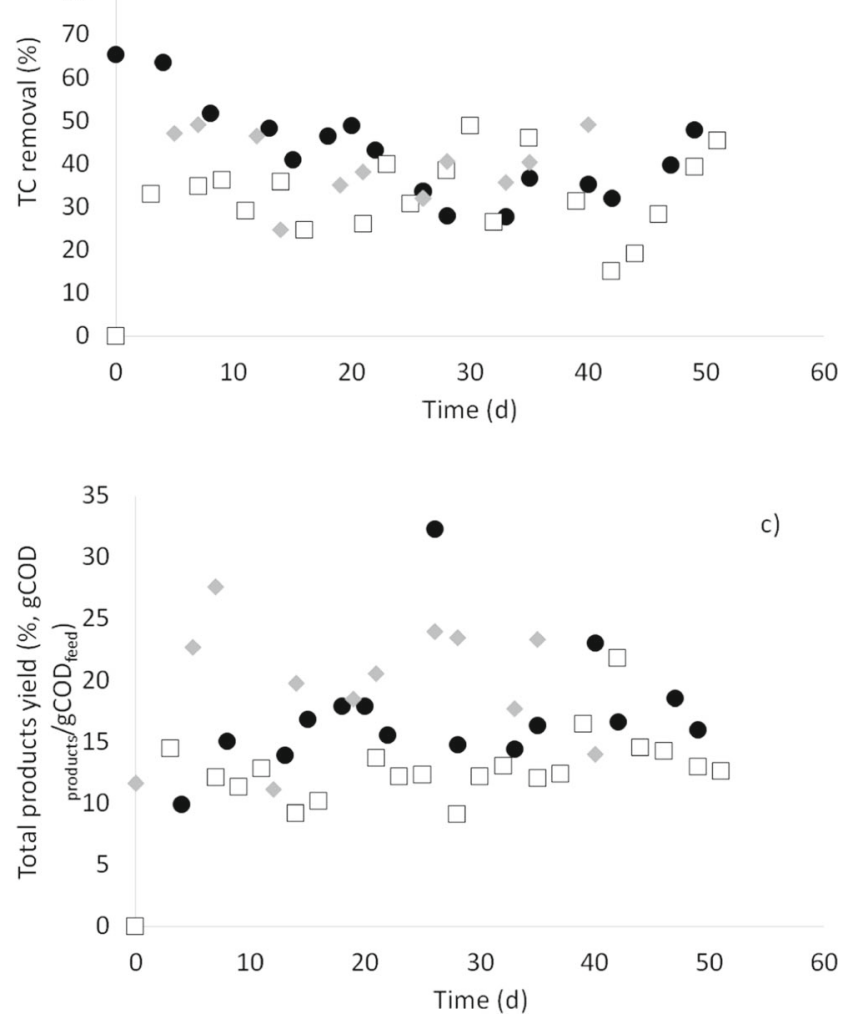

Fig. 5 Time profiles for Runs 8 and 9 compared with Run 2: no acclimation $(\square$ ), 30 days of acclimation ( $), 80$ days of acclimation $(\diamond)$. a VSS removal. b TC removal. $\mathbf{c}$ Total products yield

distribution, acetate was the main product in all the runs, whilst propionate decreased with increasing temperature.

Although some studies reported that thermophilic conditions $\left(\mathrm{T}>40^{\circ} \mathrm{C}\right)$ favour the hydrolysis and substrate removal $[21,28,29]$, these studies were usually carried out with long acclimation periods, ranging from several months to 1 year, to each temperature condition, whilst in our study, the semicontinuous runs were started immediately after inoculation, with no acclimation to the different temperatures. The effect 
Fig. 6 Average values at steady state for runs 8 and 9 compared with Run 2 (acclimation of 0,30 and 80 days): a Removal from the liquid-solid phase of VSS ( $\square$ ) and TC $(\square)$. b Product yield: acetate $(\square)$, propionate $(\square)$, butyrate $(\square)$ and ethanol $(\square)$

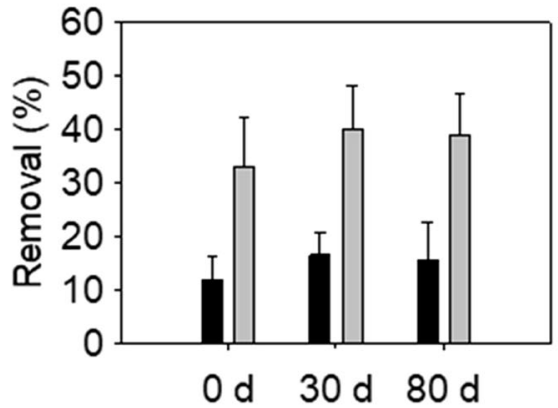

(a)

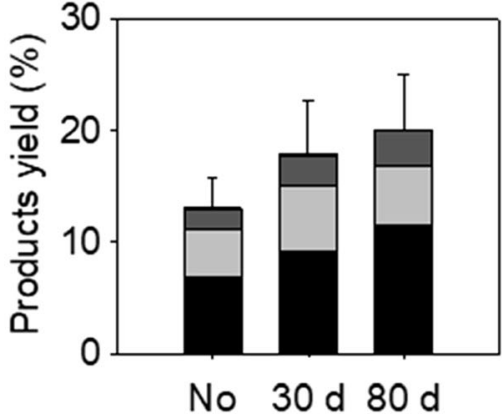

(b) of acclimation time at the different temperatures deserves further investigation.

\subsection{Effect of buffer capacity}

The effect of buffer capacity was investigated by comparing Run 13 with Run 2 . The average values of the $\mathrm{pH}$, VSS and TC removal and products yield at steady-state condition in the runs at 20 and $200 \mathrm{mM}$ phosphate buffer are shown in Fig. 8. The main difference between these experimental runs was the $\mathrm{pH}$ dropped from 6.8 to 5.0 when phosphate buffer concentration was reduced from 200 to $20 \mathrm{mM}$ (Fig. 8a). The consequent difference in $\mathrm{pH}$ affected the substrate removal and contributed to a shift in the product distribution. A higher substrate removal and product yield were obtained for the fermenter at $200 \mathrm{mM}$ of phosphate buffer and more neutral pH (Fig. 8b). Although acetic acid was still the main fermentation product for both fermenters, the production of propionic acid was more significant for the fermenter with phosphate buffer $200 \mathrm{mM}$ than for the fermenter with phosphate buffer $20 \mathrm{mM}$ (Fig. 8c). Butyrate and ethanol were obtained at very low concentration in both conditions.

The fermentation at high and low phosphate buffer concentration showed that the effect of $\mathrm{pH}$ on the fermentation performance is considerable. The strong effect of $\mathrm{pH}$ is probably due to the fact that hydrolytic enzymes produced in situ usually have an optimum activity around neutral and high $\mathrm{pH}[30$, 31]. The lower substrate removal and product yield at acidic
$\mathrm{pH}$ might also be associated to microbial inhibition due to $\mathrm{pH}$ toxicity.

The microbial inhibition at low $\mathrm{pH}$ is usually associated to the "weak-acid uncoupling" mechanism [32]. The carboxylic acids in their undissociated form at low $\mathrm{pH}$ are more permeable to the membrane cell, diffuse passively, and acidify the cytoplasm, causing inhibition of cell metabolism.

Regarding the products yield, an increased production of propionate was observed with the higher concentration of phosphate buffer (higher $\mathrm{pH}$ ). Although no study on effect of $\mathrm{pH}$ in anaerobic digestion of grass could be found, several other studies have observed how the fermentation products are distributed in a wide $\mathrm{pH}$ range $[30,33]$. The difference observed in several studies demonstrates that the product distribution is very dependent of the feedstock nature and $\mathrm{pH}$ simultaneously.

Although in this study a phosphate buffer at different concentrations was used, in full-scale digesters, the use of controlled acid or base addition could be more feasible for $\mathrm{pH}$ control. This does not alter the significance of our results on the effect of $\mathrm{pH}$ on the process.

\subsection{General discussion and significance of the results}

Whilst most literature studies on the AD of lignocellulosic feedstocks are focussed on the pre-treatment steps, this study shows that $\mathrm{AD}$ is a promising technology for the conversion of lignocellulosic substrates, at least for the substrate considered in this study, even without any hydrolytic pre-treatments.
Fig. 7 Average values at steady state for runs 10-12 compared with Run 2 (at 40, 50, 60 and $70{ }^{\circ} \mathrm{C}$ ). a Removal from the liquid-solid phase of VSS ( and TC $(\square)$. b Product yield: acetate $(\square)$, propionate $(\square)$, butyrate $(\square)$ and ethanol $(\square$

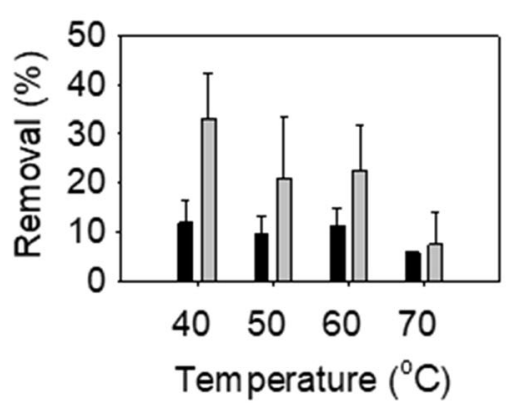

(a)

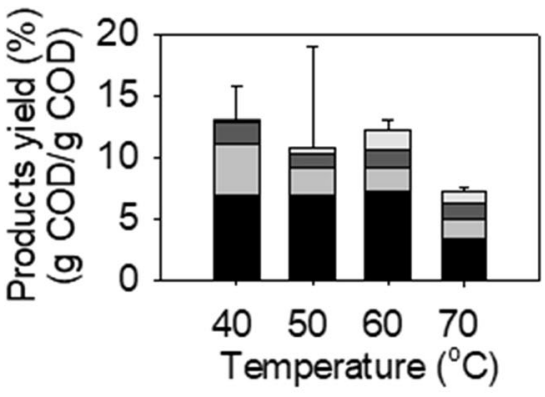

(b) 
Fig. 8 Average values at steady state condition for Run 13 compared with Run 2 (20 and $200 \mathrm{mM}$ of phosphate buffer). a $\mathrm{pH}$. b Removal from the liquidsolid phase of VSS ( $\square$ and TC (口). c Product yield: acetate $\square$, propionate $(\square)$, butyrate $\square$ ) and ethanol $(\square)$

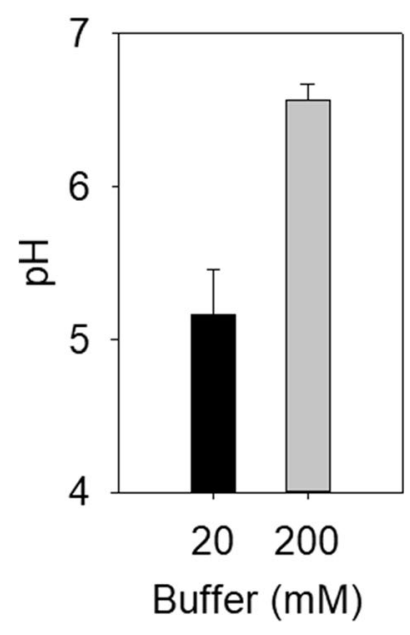

(a)

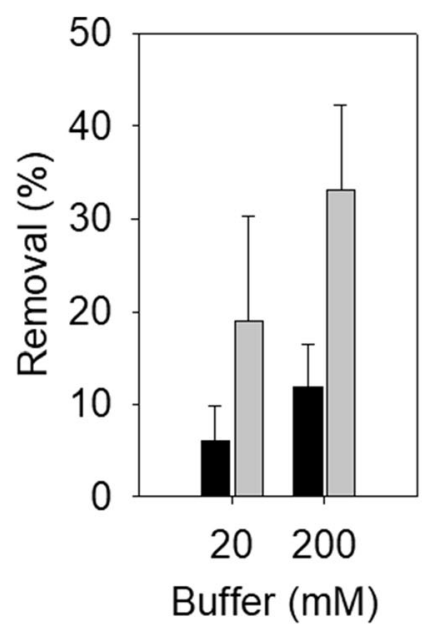

(b)

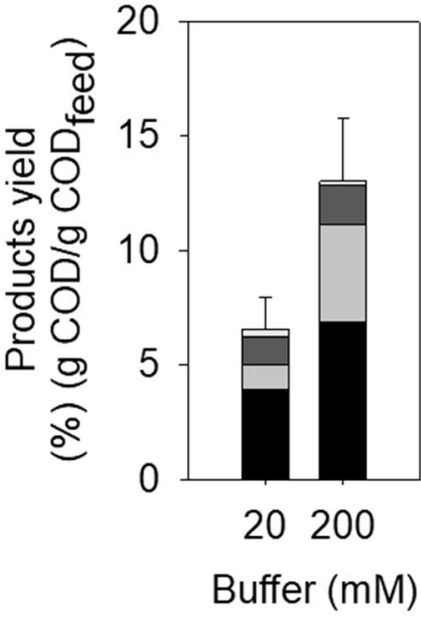

(c)
In this study, up to $20 \%$ yield (COD basis) of liquid-phase products (SRT 8 days) and up to $57 \%$ yield (COD basis) of gas-phase products (SRT 64 days) were obtained.

The SRT is the most important parameter that determines the conversion of the substrate and the type of products obtained (methane or liquid-phase products). At low SRT, the conversion of the feedstock is limited and organic acids are the main fermentation products. On the other hand, at high SRT, the conversion of the feedstock is much higher but almost no liquid-phase products are present in the effluent due to high methanogenic activity.

If the aim of the AD process is convert the lignocellulosic feedstock into methane, then long SRT values should be applied. However, in AD processes with suspended biomass and without biomass recycle, the SRT and HRT coincide; therefore, high values of the SRT correspond to large vessel volumes and, consequently, the capital expenditure becomes higher and the volumetric methane production becomes lower. In order to reduce reactor volumes, processes with long SRT and short HRT could be considered. UASB and packed bed reactors allow decoupling the SRT from the HRT; however, these processes only tolerate low concentrations of suspended solids in the feed (typically less than 1\%). The anaerobic gas lift reactor (AGR) has been proposed for the decoupling of SRT and HRT in systems with high concentrations of suspended solids in the feed [34].

If the aim of the $\mathrm{AD}$ process is to produce liquid-phase products (organic acids and ethanol), then conditions need to be found that give high conversion of the feedstock, high products concentration and no methane production. Acclimation of the microorganisms to the feedstock in batch before the start of continuous processing at low SRT can possibly improve the substrate hydrolysis. However, this study showed that even though microorganisms in batch conditions can achieve high degradation of the feedstock, when the conditions are switched to continuous with low SRT, the biodegradation of the feedstock decreases significantly. Possibly, batch acclimation coupled with longer SRT could give better process performance and avoid washing out the slow-growing microorganisms that can hydrolyse the lignocellulosic substrates. However, the SRT would still need to be short enough (e.g. 4 or 8 days) to wash out methanogenic microorganisms. As an alternative, continuous acclimation at long SRT followed by gradual reduction in the SRT could be investigated to obtain high conversion of the feedstock and wash-out of the methanogenic microorganisms.

Another interesting finding of this study is the long time required to achieve high conversion of the lignocellulosic substrate. In the run at the longest SRT (64 days), microorganisms developed their maximum degradation potential of the feedstock only after about 70 days from the start of the continuous run. This indicates the importance of allowing a long-enough acclimation time in the anaerobic digestion of lignocellulosic substrates.

This study also shows that, in addition to the SRT, $\mathrm{pH}$ and temperature are also important operational variables in determining the conversion of the feedstock and the product yield. Low $\mathrm{pH}$ values need to be avoided. Temperatures higher than $40{ }^{\circ} \mathrm{C}$ do not give any benefits in process performance, and the high temperature of $70{ }^{\circ} \mathrm{C}$ causes a significant decrease of feedstock conversion and product yield. However, the effect of $\mathrm{pH}$ and temperature has been investigated in this study at the relatively low SRT of 2 days, and further study needs to be done in a wider range of SRT values.

Another important aspect that needs further investigation is the concentration of products in the digestate. Clearly, high concentration of products needs to be obtained for an economical separation after the AD process. In this study, with a feedstock concentration of $24 \mathrm{gCOD} / 1$, the maximum products concentration obtained was $4.8 \mathrm{~g} \mathrm{COD} / 1$. In order to 
increase the product concentration in the effluent, studies with higher concentration of the feedstock are needed.

Finally, it is important to observe that the results obtained in this study depend on the feedstock used, the stage at which it was harvested and the pre-treatments used by the manufacturer. In particular, this study was carried out with a milled and dried feedstock. Milling reduces the particle size of the feedstock, increasing the surface area available for microbial attachment, the first step in microbial hydrolysis. Therefore, reaction rates with smaller particle sizes of the feedstock are likely to be higher than with larger particle size, if the hydrolysis step is controlling. More research needs to be carried out to investigate the role of the particle size of the lignocellulosic feedstock on the rate of anaerobic digestion. More in general, the effect of the nature of the lignocellulosic feedstocks on their anaerobic digestibility deserves further investigation.

\section{Conclusions}

This study has shown that high degradation of wheatgrass is possible under anaerobic conditions without pre-treatment. However, stable production of liquid-phase products (SCOAs and ethanol) was only possible at low-medium SRT (up to 8 days), and at this condition, the removal of the feedstock was limited (10-15\% removal of the VSS, up to $30 \%$ removal of TC), limiting the maximum yield of liquidphase products to $20 \%$ (COD basis). High SRT values (64 days) gave high conversion of the feedstock, but no liquid-phase products were observed and TCOD removal was up to $57 \%$, indicating that methane production was the main mechanism for substrate removal.

Acknowledgments The authors wish to acknowledge Mrs. Elizabeth Hendrie and Ms. Gabriela Paupitz for the technical collaboration and Mr. Andrew Rennie (Gask Farm, Turriff, Aberdeenshire, UK) for kindly providing the inoculum used in the experiments.

Funding information Carnegie Trust for the Universities of Scotland (Research Incentive Grant 70307), CAPES (Coordination for the Improvement of Higher Education Personnel) provided the financial support (Process 011944/2013-07),

Open Access This article is licensed under a Creative Commons Attribution 4.0 International License, which permits use, sharing, adaptation, distribution and reproduction in any medium or format, as long as you give appropriate credit to the original author(s) and the source, provide a link to the Creative Commons licence, and indicate if changes were made. The images or other third party material in this article are included in the article's Creative Commons licence, unless indicated otherwise in a credit line to the material. If material is not included in the article's Creative Commons licence and your intended use is not permitted by statutory regulation or exceeds the permitted use, you will need to obtain permission directly from the copyright holder. To view a copy of this licence, visit http://creativecommons.org/licenses/by/4.0/.

\section{References}

1. Dionisi D, Silva IM (2016) Production of ethanol, organic acids and hydrogen: an opportunity for mixed culture biotechnology? Rev Environ Sci Biotechnol 15:213-242

2. Philp JC, Ritchie RJ, Allan JE (2013) Biobased chemicals: the convergence of green chemistry with industrial biotechnology. Trends Biotechnol 31:219-222

3. Dionisi D, Bolaji I, Nabbanda D, Silva IM (2018) Calculation of the potential production of methane and chemicals using anaerobic digestion. BioFPR 12:788-801

4. Carrere H, Antonopoulou G, Affes R, Passos F, Battimelli A, Lyberatos G, Ferrer I (2016) Review of feedstock pretreatment strategies for improved anaerobic digestion: from lab-scale research to full-scale application. Bioresour Technol 199:386-397

5. Hassan M, Ding W, Bi J, Mehryar E, Talha ZAA, Huang H (2016) Methane enhancement through oxidative cleavage and alkali solubilization pre-treatments for corn stover with anaerobic activated sludge. Bioresour Technol 200:405-412

6. Canizo JR, Cortes-Callejas ML, Davila-Gomez FJ, Heredia-Olea E, Perez-Carrillo E, Serna-Saldívar SO (2014) Release of potentially fermentable sugars during dilute acid treatments of Bermuda grass NK37 (Cynodon dactylon) for second-generation ethanol production. J Chem Technol Biotechnol 89:1941-1947

7. Kandel TP, Sutaryo S, Møller HB, Jørgensen U, Lærke PE (2013) Chemical composition and methane yield of reed canary grass as influenced by harvesting time and harvest frequency. Bioresour Technol 130:659-666

8. Sotola J (1940) The chemical composition and apparent digestibility of nutrients in crested wheatgrass harvested in three stages of maturity. J Agric Res 61(4):303

9. Brown PH, Graham RD, Nicholas DJD (1984) The effects of manganese and nitrate supply on the levels of phenolics and lignin in young wheat plants. Plant Soil 81:437-440

10. Benincasa P, Galieni A, Manetta AC, Pace R, Guiducci M, Pisante M, Stagnari F (2015) Phenolic compounds in grains, sprouts and wheatgrass of hulled and non-hulled wheat species. J Sci Food Agric 95(9):1795-1803

11. Bichot A, Delgenes J-P, Mechin V, Carrere H, Bernet N, GarciaBernet D (2018) Understanding biomass recalcitrance in grasses for their efficient utilization as biorefinery feedstock. Rev Environ Sci Biotechnol 17:707-748

12. Bulk Powders (2019) Wheatgrass Nutrition Information. Available at https://www.bulkpowders.co.uk/wheatgrass-powder.html\#navnutrition. Accessed on 10/12/19

13. Gu Y, Chen X, Liu Z, Zhou X, Zhang Y (2014) Effect of inoculum sources on the anaerobic digestion of rice straw. Bioresour Technol 158:149-155

14. Dionisi D (2017) Biological wastewater treatment processes. Mass and Heat Balances. CRC Press, Boca Raton

15. Kalyuzhnyi SV (1997) Batch anaerobic digestion of glucose and its mathematical modeling. II. Description, verification and application of model. Bioresour Technol 59(2):249-258

16. Ekama GA, Sötemann SW, Wentzel MC (2007) Biodegradability of activated sludge organics under anaerobic conditions. Water Res 41(1):244-252

17. Borja R, Martin A, Durán MM, Luque M, Alonso V (1994) Kinetic study of anaerobic digestion of brewery wastewater. Process Biochem 29(8):645-650

18. Sivagurunathan P, Kumar G, Bakonyi P, Kim S-H, Kobayashi T, Xu KQ, Lakner G, Tóth G, Nemestóthy N, Bélafi-Bakó K (2016) A critical review on issues and overcoming strategies for the enhancement of dark fermentative hydrogen production in continuous systems. Int J Hydrog Energy 41:3820-3836 
19. Turick CE, Peck MW, Chynoweth DP, Jerger DE, White EH, Zsuffa L, Kenney W (1991) Methane fermentation of woody biomass. Bioresour Technol 37:141-147

20. Voelklein MA, Rusmanis D, Murphy JD (2016) Increased loading rates and specific methane yields facilitated by digesting grass silage at thermophilic rather than mesophilic temperatures. Bioresour Technol 9:486-493

21. Ghasimi DS, Tao Y, Kreuk M, Zandvoort MH, Lier JB (2015) Microbial population dynamics during long-term sludge adaptation of thermophilic and mesophilic sequencing batch digesters treating sewage fine sieved fraction at varying organic loading rates. Biotechnol Biofuels 8:171

22. Tong X, Smith LH, McCarty PL (1990) Methane fermentation of selected lignocellulosic materials. Biomass 21:239-255

23. Sharma SK, Mishra IM, Sharma MP, Saini JS (1988) Effect of particle size on biogas generation from biomass residues. Biomass $17: 251-263$

24. Silva IMO, Dionisi D (2016) Anaerobic digestion of wheatgrass under mesophilic and thermophilic conditions and different inoculum sources. Chem Eng Trans 50:19-24

25. Romano RT, Zhang R, Teter S, McGarvey JA (2009) The effect of enzyme addition on anaerobic digestion of JoseTall wheat grass. Bioresour Technol 100:4564-4571

26. Lalak J, Kasprzycka A, Martyniak D, Tys J (2016) Effect of biological pretreatment of Agropyron elongatum 'BAMAR'on biogas production by anaerobic digestion. Bioresour Technol 200:194 200

27. Buitrón G, González A (1996) Characterization of the microorganisms from an acclimated activated sludge degrading phenolic compounds. Water Sci Technol 34(5/6):289-294
28. Min K, Park K, Jung Y, Khan A, Kim Y (2002) Acidogenic fermentation: utilization of wasted sludge as a carbon source in the denitrification process. Environ Technol 23:293-302

29. Moset V, Poulsen M, Wahid R, Højberg O, Møller HB (2015) Mesophilic versus thermophilic anaerobic digestion of cattle manure: methane productivity and microbial ecology. Microb Biotechnol 8:787-800

30. Veeken A, Kalyuzhnyi S, Scharff H, Hamelers B (2000) Effect of $\mathrm{pH}$ and VFA on hydrolysis of organic solid waste. J Environ Eng 126:1076-1081

31. Garcia-Aguirre J, Aymerich E, de Goñi JG, Esteban-Gutiérrez M (2017) Selective VFA production potential from organic waste streams: assessing temperature and $\mathrm{pH}$ influence. Bioresour Technol 244:1081-1088

32. Abbott DA, Knijnenburg TA, De Poorter LM, Reinders MJ, Pronk JT, Van Maris AJ (2007) Generic and specific transcriptional responses to different weak organic acids in anaerobic chemostat cultures of Saccharomyces cerevisiae. FEMS Yeast Res 7:819-833

33. Temudo MF, Kleerebezem R, van Loosdrecht M (2007) Influence of the $\mathrm{pH}$ on (open) mixed culture fermentation of glucose: a chemostat study. Biotechnol Bioeng 98:69-79

34. Begum S, Ahuja S, Anupoju GR, Kuruti K, Juntupally S, Gandu B, Ahuja DK (2017) Process intensification with inline pre and post processing mechanism for valorization of poultry litter through high rate biomethanation technology: a full scale experience. Renew Energy 114:428-436

Publisher's Note Springer Nature remains neutral with regard to jurisdictional claims in published maps and institutional affiliations. 